\title{
Geomorphometric characterisation of natural and anthropogenic land covers
}

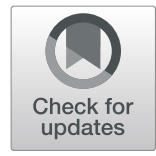

Wenfang Cao ${ }^{* *}$, Giulia Sofia ${ }^{2}$ and Paolo Tarolli ${ }^{1}$

\begin{abstract}
The scientific community has widely discussed the role of abiotic and biotic forces in reshaping the Earth's surface. Currently, the literature is debating whether humans are leaving a topographic signature on the landscape. Apart from the influence of humans on processes, does the resulting landscape bear an unmistakable signature of anthropogenic activities? This research analyses from a statistical point of view the morphological signature of anthropogenic and natural land covers in different topographic context, as a fundamental challenge in the emerging debate of human-environment relationships and the modelling of global environmental change. It aims to explore how intrinsically small-scale processes, related to land use, can influence the form of entire landscapes and to determine whether these processes create a distinctive topography. The work focusses on four study areas in floodplains, plain to hilly, hills and mountains, for which LiDAR-derived Digital Terrain Models (DTMs) are available. Surface morphology is described with different geomorphometric parameters (slope, mean curvature and surface peak curvature) and their frequency distribution. The results show that the distribution of geomorphometric indices can reveal anthropogenic land covers and landscapes. In most cases, different land covers show statistically significant differences $(p<0.05)$ in their morphology. Finally, this study demonstrates the possibility to use a geomorphic analysis to quantify anthropogenic impact based on land covers in different landscape contexts. This provides useful insight into understanding the impact of human activities on the present morphology and offers a comprehensive understanding of coupling human-land interaction from a geomorphological point of view.
\end{abstract}

Keywords: Geomorphology, Geomorphometry, Anthropogenic impact, Land cover

\section{Introduction}

Landforms represent the long-term development of geologic and geomorphologic processes (Bolongaro-Crevenna et al. 2005; Oldroyd and Grapes 2008; Kleman et al. 2016). They tend to reflect the interaction of climate, tectonics, erosion and deposition (Castelltort et al. 2015; Zhang et al. 2016; Marshall et al. 2017). An increasing amount of the research (Szabó et al. 2010; Hooke 2012; Ellis et al. 2013; Goudie and Viles 2016; Tarolli and Sofia 2016; Tarolli 2016; Brown et al. 2017; Migoń and Latocha 2018; Goudie 2018; Tarolli et al. 2019) has pointed out that human activity has played a pivotal role as geomorphic forcing. For instance, agriculture is susceptible to accelerate soil erosion (Tóth 2010; Curebal et al. 2015; Borrelli et al. 2017), dams and reservoirs engineering interrupt the continuity

\footnotetext{
* Correspondence: wenfang.cao@phd.unipd.it

1 Department of Land, Environment, Agriculture and Forestry, University of

Padova, Agripolis, viale dell'Università 16, Legnaro (PD) 35020, Italy

Full list of author information is available at the end of the article
}

of sediment transport in rivers system (Tessler et al. 2016; Wang et al. 2016; Poeppl et al. 2017), road network construction is associated with slope stability of roadcut and other geological risks (Csima 2010; Sidle and Ziegler 2012; Penna et al. 2014; Ramos-scharrón 2018).

With this literature, the concept of surface reshaping from both abiotic and biotic forces has emerged (Ellis 2004; Steiger and Corenblit 2012; Pietrasiak et al. 2014; Tarolli and Sofia 2016). As suggested by Dietrich and Perron (2006), small-scale biotic processes can influence the form of landscapes and create a distinctive topography, but this has yet to be investigated for human-made landforms. Identifying natural and anthropogenic features and further distinguishing the landform signatures still poses a significant challenge for the geomorphological community (Tarolli et al. 2019). Thanks to the progress in remote sensing techniques and open-access datasets, the recognition of large-scale geomorphic signatures is now possible at various scales (Evans 1980; Nagel et al. 2014; 


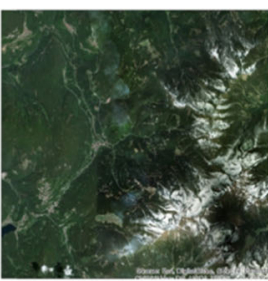

(d) Trentino

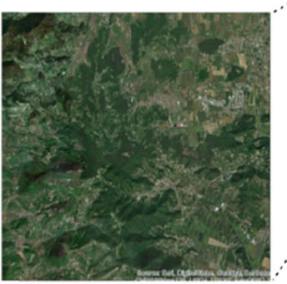

(b) Colli Euganei

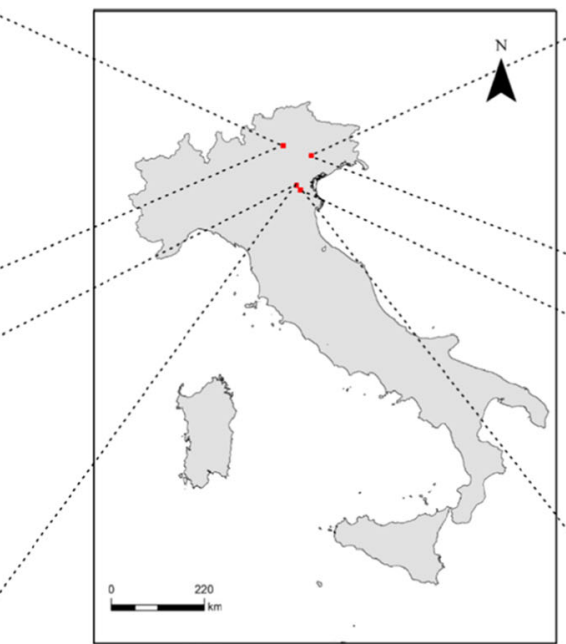

$-{ }^{220}$

Fig. 1 Considered four study areas: a floodplain, b plain to hilly, $\mathbf{c}$ hilly, $\mathbf{d}$ mountain

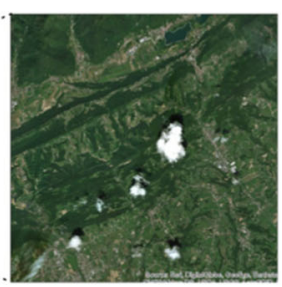

(c) Venetian Prealps

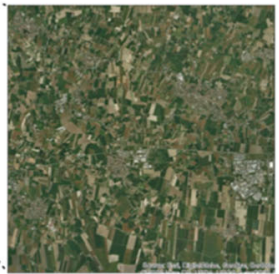

(a) Veneto Floodplain
Sofia et al. 2014a; Tarolli 2014; Byun and Seong 2015; Jordan et al. 2016). However, an explicit characterisation, from a morphological point of view, of natural and anthropogenic surfaces and for different landscape contexts, is still missing. This study showcases how high-resolution topographic data can offer the basis to (1) characterise specific signatures with land covers on the basis of an objective geomorphometric analysis; (2) demonstrate that the anthropogenic and natural land covers show a statistically different underlining morphology and (3) understand (where present) the degree of anthropogenic impact due to the various land covers.
Since a significant concern is how natural systems are being modified or transformed by anthropogenic land uses, one crucial issue is how the different land surface should be disaggregated for modelling and further analysis, and if any generic relationships can be identified between land uses and morphological transformations to the landscape. Geosciences must advance towards empirical and theoretical frameworks that integrate the natural and sociocultural forces that are now among the leading shapers of Earth's surface processes (Tarolli et al. 2019) to understand the causes and consequences of these transformations and contribute to building a sustainable future. This work (a)

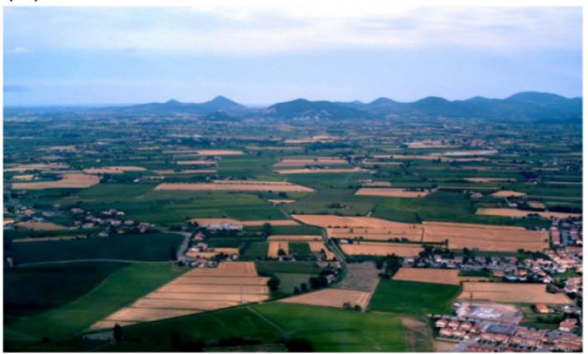

(c)

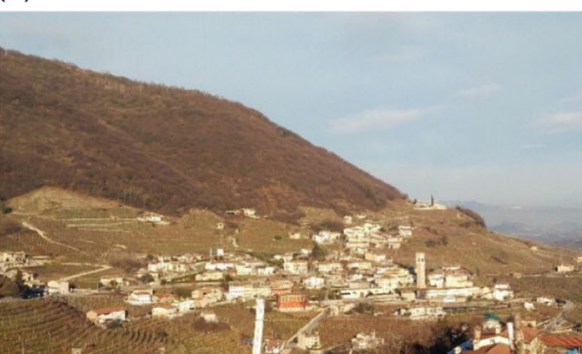

(b)

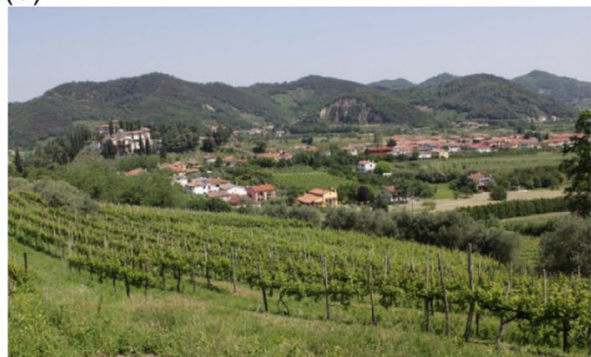

(d)

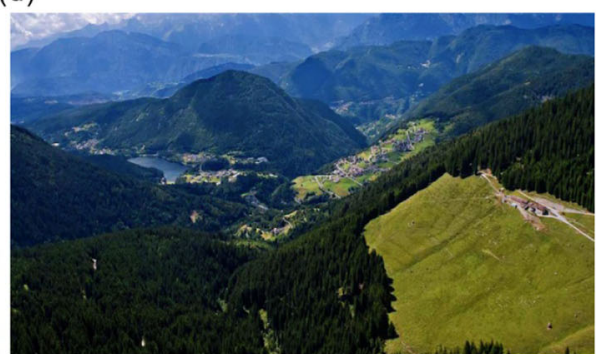

Fig. 2 The field overview of the study areas: a floodplain, $\mathbf{b}$ plain to hilly, c hilly, $\mathbf{d}$ mountain (photo in 2a by P. Claudio; photo in 2b by M. Luca; photo in 2c by B. Eros, photo in 2d from www.abfotografia.it) 
offers an example of such an empirical framework, providing a diagnostic tool to infer objectively morphological differences within various landscapes. Processes happen in three dimensions and observing the topographic differences among land covers offer a basis to potentially infer differences in the processes happening in these landscapes.

\section{Study area}

This study investigates four study areas of $10 \times 10 \mathrm{~km}$ in northeastern Italy, representing different landscapes, from floodplains to mountains (Fig. 1): the Veneto floodplain (floodplain, Fig. 1a), Colli Euganei (plain to hilly, Fig. 1b), Venetian Prealps (hilly, Fig. 1c) and Trentino (Alpine mountains, Fig. 1d). These sites were selected because they share close geographic locations and distributions of land covers, but they differ in landforms.

The elevations in Veneto floodplain (Fig. 1a) range from -2 to $10 \mathrm{~m}$ a.s.l., with an average of $4 \mathrm{~m}$ a.s.l. Seventy-five percent of the area has a height lower than
$5 \mathrm{~m}$ a.s.l. This area is characterised by a higher level of anthropogenic pressure, especially agricultural landscapes, due to urbanisation and industrialisation. The area is intensively drained for reclamation and irrigation purposes through a dense network of channels and ditches (Fig. 2a). The plain to hilly area (Fig. 1b) has an elevation ranging from 0.4 to $601 \mathrm{~m}$ a.s.l. (average $112 \mathrm{~m}$ a.s.l.). Seventy-eight percent of the area has a height lower than $200 \mathrm{~m}$ a.s.l. These hills are of volcanic origins and rise between 300 and $600 \mathrm{~m}$. Vineyard cultivation is widespread in this area (Fig. 2b). The elevation in hilly area (Fig. 1c) ranges between 88 and $889 \mathrm{~m}$ a.s.l. (average $251 \mathrm{~m}$ a.s.l.). Ninety-five percent of the area is concentrated on the height between 100 and $500 \mathrm{~m}$ a.s.l. As in the Euganei, vineyard is also a typical characteristic of this area (Fig. 2c). The fourth area (Figs. 1d and 2d) is an Alpine landscape. The elevation ranges from 541 to $2488 \mathrm{~m}$ a.s.l. with a mean value of $1577 \mathrm{~m}$ a.s.l. Eighty percent of the area has the height from 1000 to $2000 \mathrm{~m}$ a.s.l. (a)

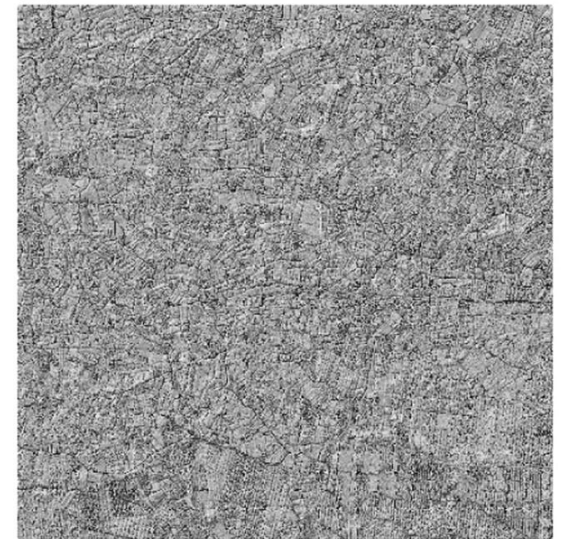

(c)

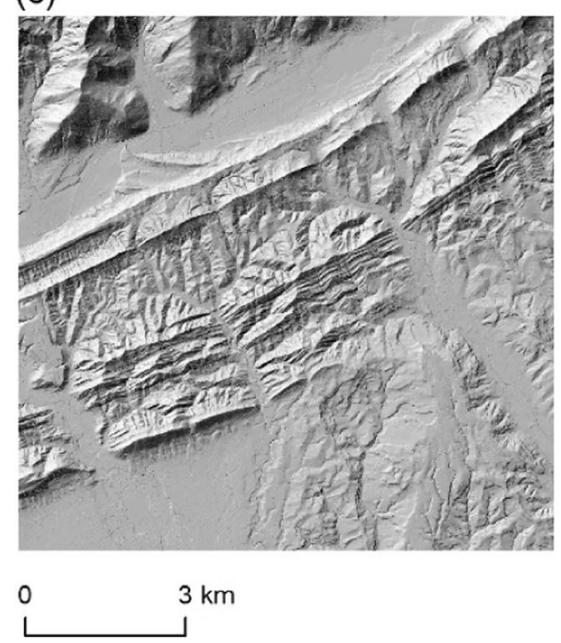

(b)

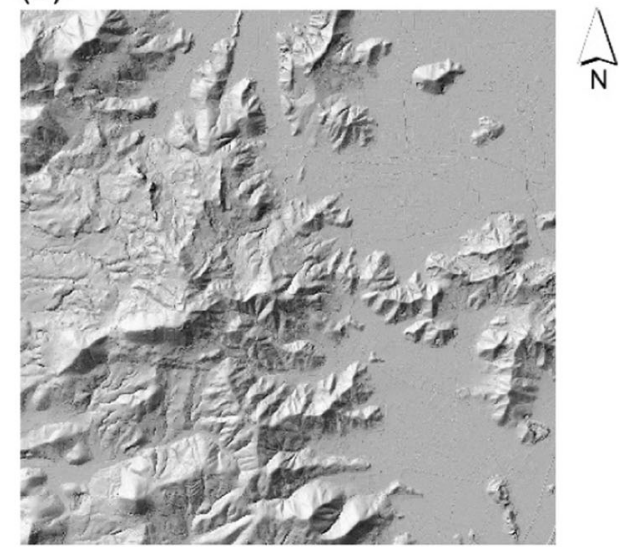

(d)

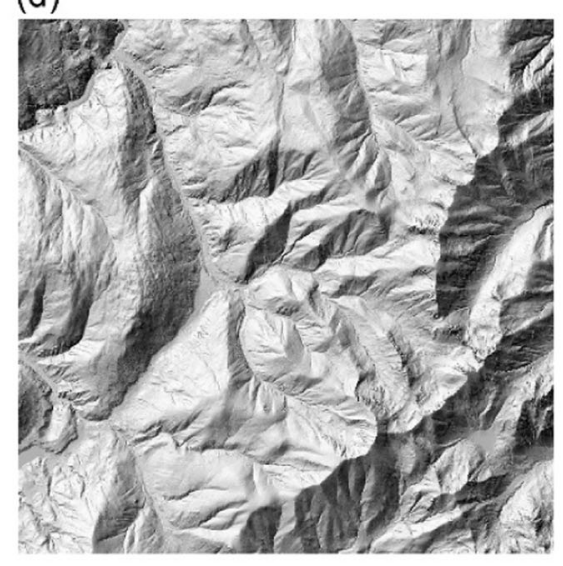

Fig. 3 LiDAR DTMs of the four study areas: a floodplain, b plain to hilly, $\mathbf{c}$ hilly, $\mathbf{d}$ mountain 


\section{Method}

\section{Data}

Light detection and ranging-derived digital terrain models (DTMs) at 2-m resolution (Fig. 3) are available thanks to public authorities in Italy (Italian Ministry for Environment, Land and Sea; Treviso Province; Trentino Alto-Adige Autonomous Region). The datasets refer to the year's range 2010-2012.

Information about land cover is available through the Corine-Land-Cover database (CLC, Coordination of Information on the Environment Land Cover) classification, as also reported by the local authorities. The considered CLC data come from an updated version of the Urban Atlas (European Environment Agency 2012) provided by the local government (Regione del Veneto 2012). The original Urban Atlas is mainly based on the combination of statistical image classification and visual interpretation of very high resolution (VHR) satellite imagery. Multispectral SPOT 5 \& 6 and Formosat- 2 pansharpened imagery with a 2-to $2.5-\mathrm{m}$ spatial resolution is used as input data. The built-up classes are combined with density information on the level of sealed soil derived from the high-resolution layer imperviousness to provide more detail in the density of the urban fabric (European Environment Agency 2012). The updated version was enriched by the local government (Regione del Veneto) with functional information (road network, services, utilities...) using ancillary data sources such as regional cartography, forest inventories, road network graphs, aerial photographs and ground surveys.

For the purpose of this work, we focused on artificial surfaces, agriculture and forest (level 1 of the CLC classification). However, due to the large-scale cultivation of vineyard in the plain to hilly and hilly areas, which we expect to have a significant impact on the morphology of the surfaces, we defined vineyard as an independent classification from agriculture. As well, we considered grass as an independent land cover because it may occur naturally or as the result of human activity (pastures, park and recreational sites), and this allows us to understand better the associated anthropogenic impact on land covers. The land cover classification can be seen from Fig. 4.

\section{Geomorphometric parameters}

To make quantitative measurements of landscape properties, we considered three geomorphometric parameters: slope and mean curvature proposed by Evans (1980) and the Spc developed by Sofia et al. (2014a).

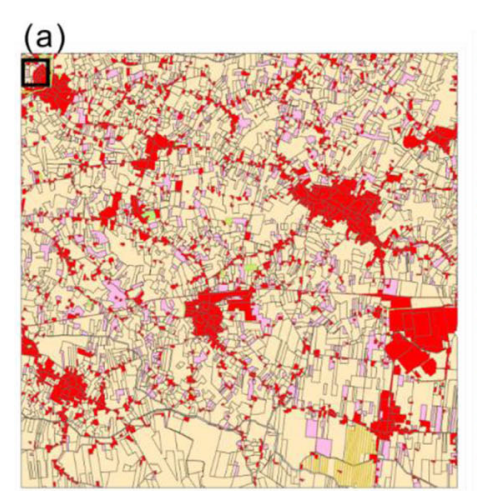

(c)

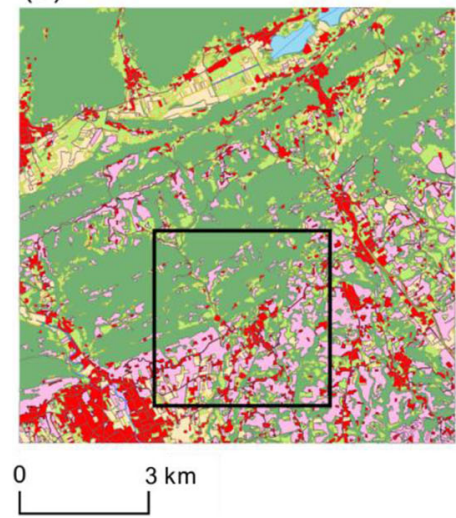

(b)

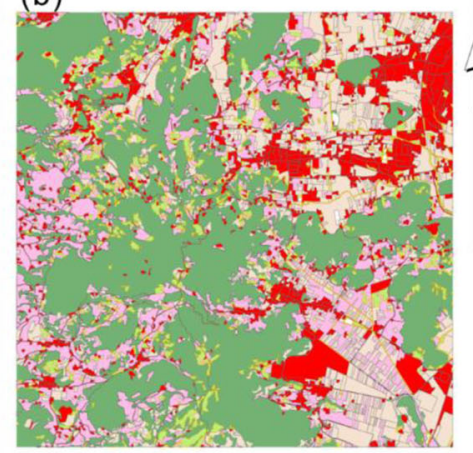

(d)

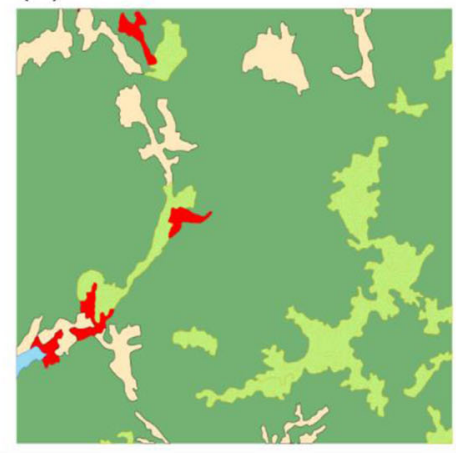
$\widehat{N}$

Land cover

crop

artificial

forest grass vineyard

Fig. 4 The land cover classification (Corine Land Cover related to 2012) in the study areas: a floodplain, b plain to hilly, c hilly, d mountain. The black rectangle areas are the case studies in Fig. 12 


\section{Slope and curvature}

Evans (1980) describes the DTM surface is approximated to a bivariate quadratic function in the form of:

$$
Z=a x^{2}+b y^{2}+c x y+d x+e y+f
$$

where $x, y$ and $z$ are local coordinates, and $a$ to $f$ are quadratic coefficients.

From such a surface, it is possible to compute the first (slope, Eq. (2)) and second (curvature, Eq. (5)) derivative. Slope (Fig. 5) is calculated as:

$$
\text { Slope }=\arctan \sqrt{d^{2}+e^{2}}
$$

where $d$ and $e$ are coefficients from Eq. $\mathrm{s}(1)$.

Curvature is the second derivative of the surface, also referred to the change rate of slope gradient or direction (Wilson and Gallant 2000), and it emphasises convex and concave elements in the landscape. Evans (1980) proposes two measure of curvature, maximum and minimum, and Wood (1996) testifies that only the resolution of the DTM and the neighbouring cells relevant to these parameters and further defined as

$$
\begin{aligned}
& \text { curvature }_{\max }=k \times g\left(-a-b+\sqrt{(a-b)^{2}+c^{2}}\right) \\
& \text { curvature }_{\min }=k \times g\left(-a-b-\sqrt{(a-b)^{2}+c^{2}}\right)
\end{aligned}
$$

where $a, b$ and $c$ are quadratic coefficients from Eq. (1), $g$ is the grid resolution of the DTM $(2 \mathrm{~m})$ and $k$ is the size of the moving window.

From the Eq. (3) and (4), mean curvature (Fig. 6) can be defined as:

$$
\text { curvature }_{\text {mean }}=\frac{\text { curvature }_{\max }+\text { curvature }_{\min }}{2}
$$

\section{Surface peak curvature}

The $S p c$ is inversely correlated with anthropogenic pressure (Chen et al. 2015; Sofia et al. 2016; Xiang et al. 2018). Surface morphology (slope) of regions presenting anthropogenic structures tends to be well organised (low $S p c$ ) and, in general, self-similar at a long distance. The basis for the evaluation of the Spc is the Slope Local Length of Auto- (a)

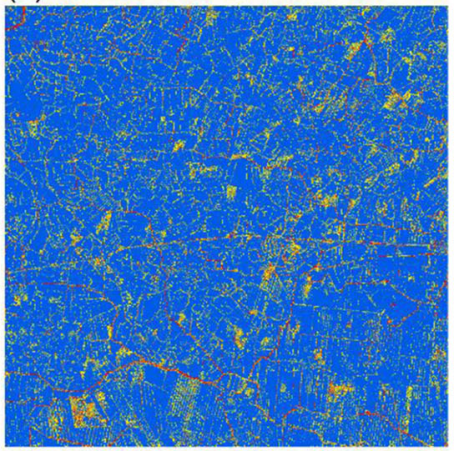

(c)

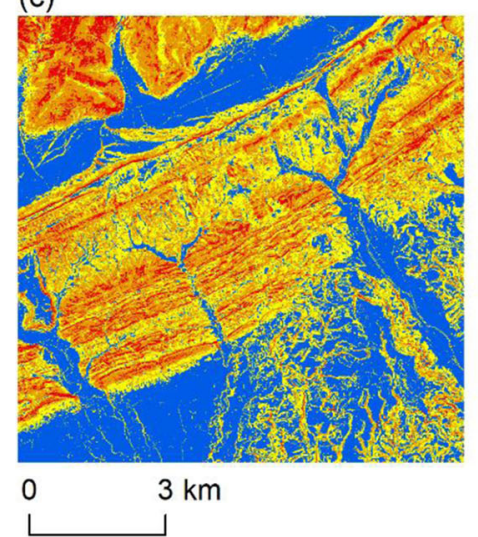

(b)
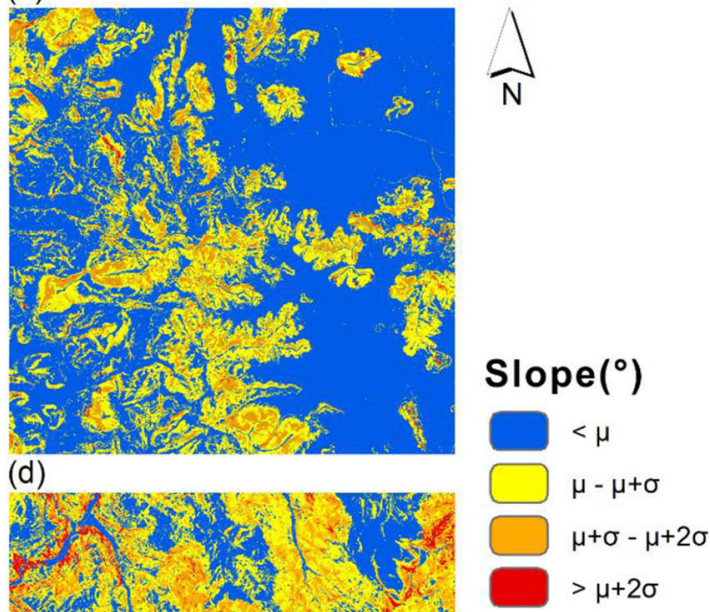

$\widehat{N}$

(1) (d)

Slope $\left({ }^{\circ}\right)$

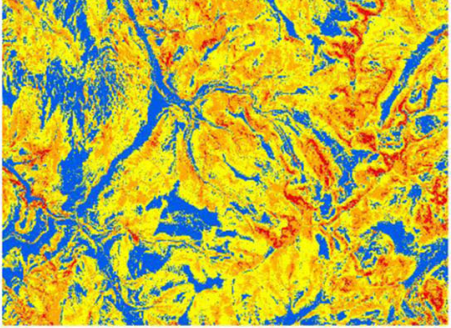




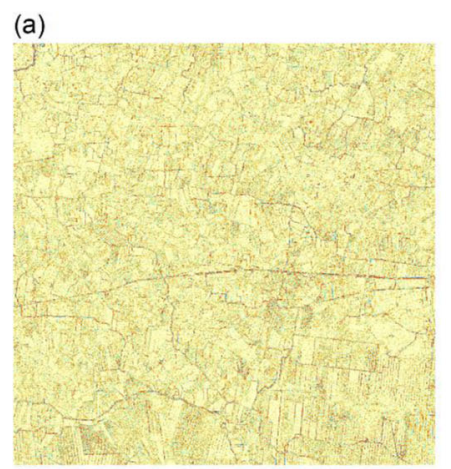

(c)

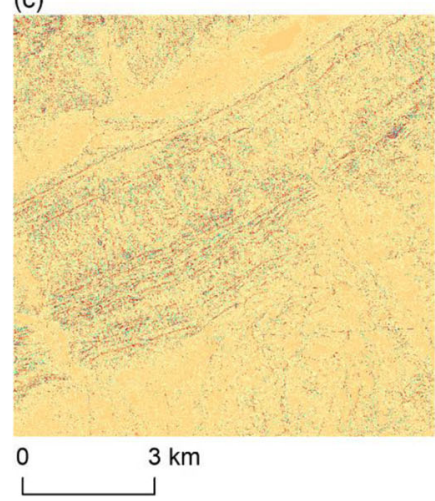

(b)

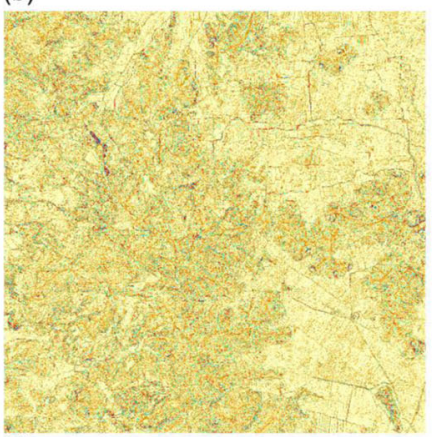

(d)

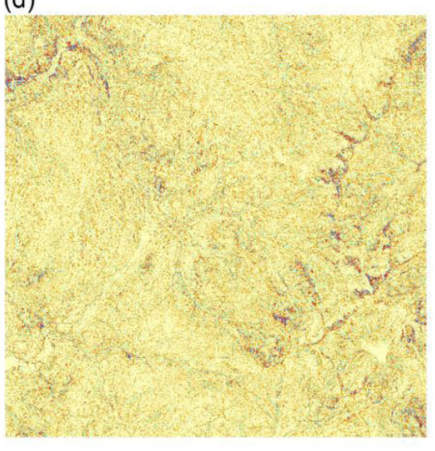

$\widehat{A}_{N}$

Mean curvature $\left(\mathrm{m}^{-1}\right)$

$\longrightarrow<-2 \sigma$

$\mu-2 \sigma-\mu-\sigma$

$\mu-\sigma-\mu$

$\mu-\mu+\sigma$

$\mu+\sigma-\mu+2 \sigma$

$>\mu+2 \sigma$

Fig. 6 Mean curvature maps for the four study areas: a floodplain, b plain to hilly, c hilly, d mountain. Mean curvature is colour-coded according to 1 to 2 times intervals of standard deviation $\sigma$ from the mean $\mu$

Correlation (SLLAC). This index quantifies the local selfsimilarities of slope (Sofia et al. 2014a). It is based on the (demonstrated) assumption that natural areas present low correlations within a neighbourhood because they are inherently irregular, while artificial surfaces to satisfy human needs for mobility and machine access tend to display a higher level of selfsimilarity with surroundings (Sofia et al. 2014a; Xiang et al. 2019). Describing the algorithm in detail is beyond the scope of this study: the authors refer to Sofia et al. (2014a) for a complete description of the procedure and to other examples of applications (Chen et al. 2015; Sofia et al. 2016; Tarolli and Sofia 2016; Xiang et al. 2018; Xiang et al. 2019).

Briefly, the steps to obtain the Spc (Fig. 7) are as follows:

1) Evaluate correlation between a moving window $(W)$ and a patch $(T)$ centred at the centre of the moving window. The implemented algorithm computes a normalised crosscorrelation between a template and the patch, in the spatial frequency domain, and reports a standardised value that ranges between 0 (no correlation) and 1 (perfect correlation).
The larger the absolute values, the stronger of the correlation.

$$
\operatorname{Corr}_{(i, j)}=\frac{\sum_{u, v}\left(W_{(i+u, j+v)}-\bar{W}_{i, j}\right)\left(T_{u, v}-\bar{T}\right)}{\left(\sum_{u, v}\left(W_{(i+u, j+v)}-\bar{W}_{i, j}\right)^{2} \sum_{u, v}\left(T_{u, v}-\bar{T}\right)^{2}\right)^{0.5}}
$$

2) Evaluate the correlation length $(L)$ thresholding at 37\% (ISO 2013; Whitehouse 2011), the maximum correlation value (Eq. (6)). The length of correlation is the length of the longest line passing through the central pixel and connecting two boundary pixels on the extracted area connected to the central pixel (SLLAC map in Additional file 1).

3) Evaluate the $S p c$ (surface peak curvature) of the SLLAC map defined as:

$$
\mathrm{Spc}=-\frac{1}{2 n} \sum_{i=1}^{n}\left[\left(\frac{\partial^{2} z(x, y)}{\partial^{2} x}\right)+\left(\frac{\partial^{2} z(x, y)}{\partial^{2} y}\right)\right],
$$

for every peak (pixel higher than its eight nearest neighbours). Where $z$ stands for SLLAC value, $x$ and $y$ represent the cell spacing, $n$ is the number of considered peaks. 

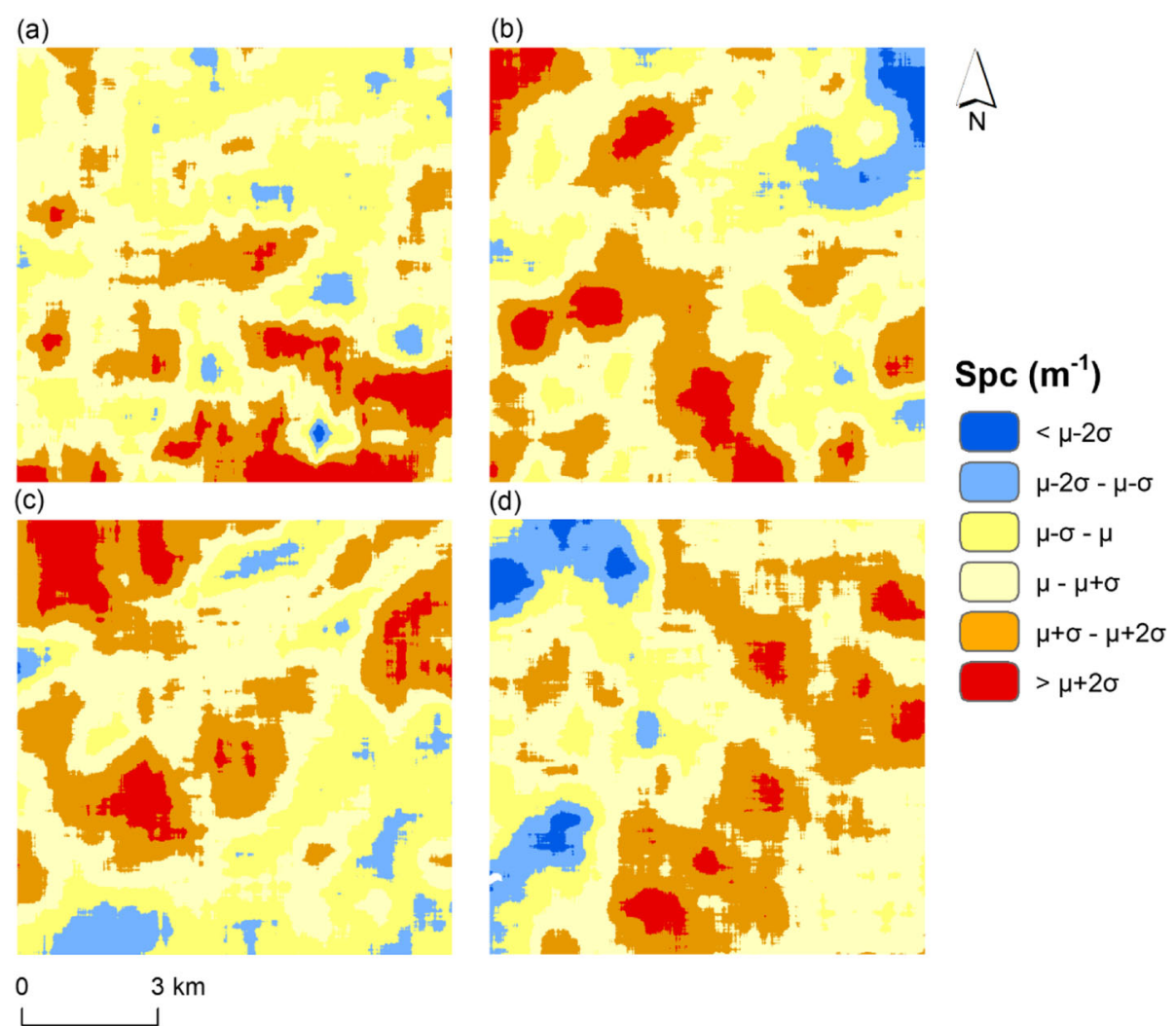

Fig. 7 SpC maps for the four study areas: a floodplain, $\mathbf{b}$ plain to hilly, $\mathbf{c}$ hilly, $\mathbf{d}$ mountain. Spc is colour-coded according to 1 to 2 times intervals of standard deviation $\sigma$ from the mean $\mu$

Please refer to the supplement to infer statistic values (mean, median, STD, MAD, skewness...) of each geomorphometric parameters within each land cover.

\section{Statistical analysis}

We expect that the topographic signature of anthropogenic activities may be more subtle than the presence of a specific landform and that it would likely be a signature on the frequency of occurrence of the various degrees of the investigated landscape properties (slope, curvature, Spc). That is, the frequency distributions of these measurements would be very different, even though all observed landform types would be found in both natural or anthropogenically modified landscapes. Therefore, we observed the probability density function (PDF) of the considered landscape parameters to (1) investigate statistical differences in geomorphological surfaces between land covers under different landforms contexts and (2) explore the specific topographic signatures of land uses. For this work, the PDFs are a probability density estimate for the sampled data. The estimate is based on a normal kernel function and is evaluated at equally spaced points that cover the range of the sampled data. The distance between points is chosen automatically, based on the range of values. This means that it can be very narrow $(<0.001)$ for landscape parameter with small magnitude. In these cases, the PDFs can reach values much greater than 1 , but their integral over any interval is always less or equal to 1 .

After statistically ensuring that the datasets did not present a normal distribution and they exhibit heteroscedasticity, we decided to consider a Kruskal-Wallis test (McKight and Najab 2010) to evaluate whether there were significant differences between landscape properties underneath a specific land cover, across multiple landscapes, and we set a $p$ value threshold of 0.05 for significance. The null hypothesis for this test is that the data for each group are statistically equal.

To investigate the similarities in PDFs between land covers, we applied the two-sample Kolmogorov-Smirnov test, which specifies the equality of probability distribution between two samples (Wilcox 2005; Razali and Wah 2011). One thousand points within each land cover were randomly selected and tested ten times to ensure the robustness of the results.

\section{Results and discussion}

Signatures recognition with different land covers

The PDF of slope (Fig. 8) exhibits very different appearances throughout the investigated landscapes. The central tendency moves from lower value to higher value, and the PDF 

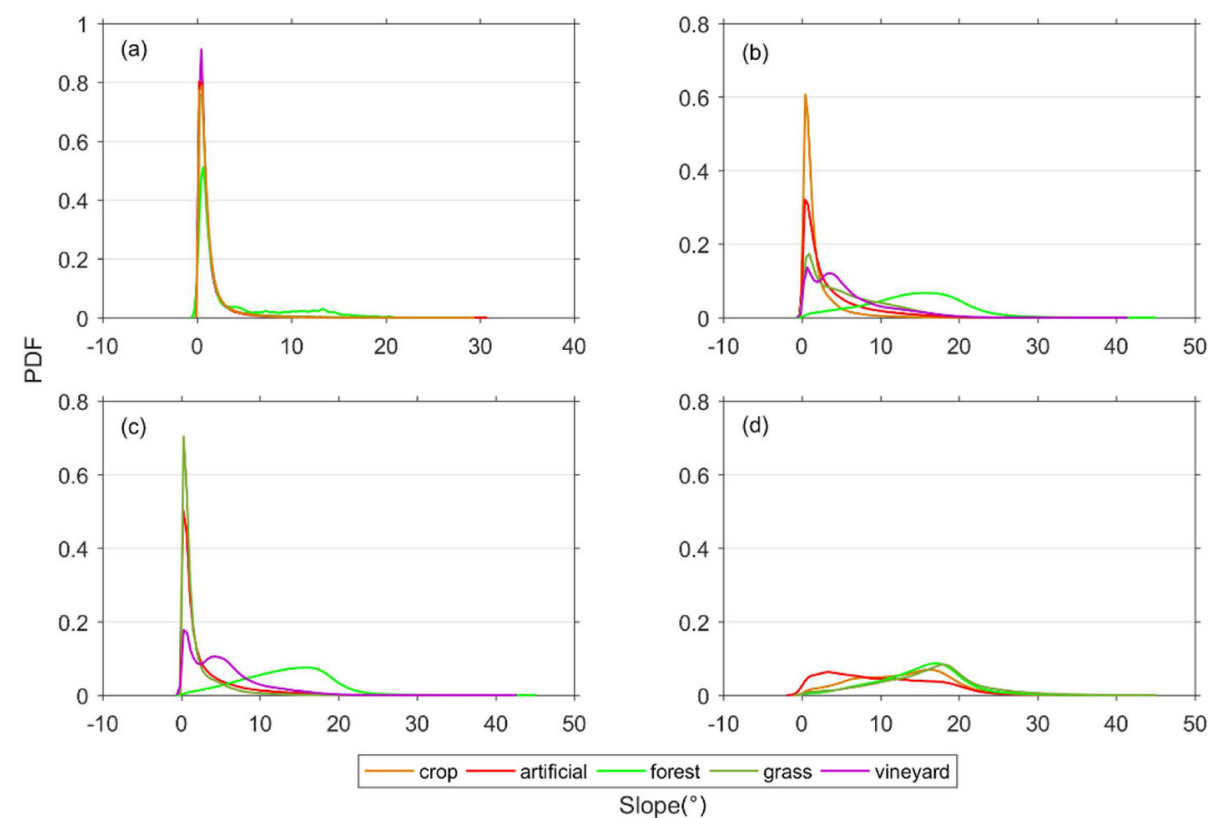

Fig. 8 The PDFs of the slope with different land covers in the four study areas: a floodplain, $\mathbf{b}$ plain to hilly, $\mathbf{c}$ hilly, $\mathbf{d}$ mountain. The vineyard in plain to hilly (b) and hilly (c) areas present bimodal curve

itself tends to be more dispersed, as we increase landscape elevation. Even though the slope PDFs are always skewed, those in steeper topography present (as expected) a much longer tail than that of more gentle landscapes (i.e. floodplain). Taking a closer view of land cover distributions, the forest distribution in hilly and mountain areas present lower skewness respect to that in the floodplain. As well, most of the land covers in the mountain site show lower asymmetry. This could be an underlining symptom that humans activities are less marked in the mountains rather than in floodplains. Sofia et al. (2017) showed, for the Veneto region, different trends in anthropogenic expansion depending on the topographic location, highlighting a significant pressure in floodplains rather than in high mountains. Other works also highlighted how anthropogenic processes in the Alps are not fundamentally different from the processes in the floodplains, but they occur with a time lag and on a smaller scale (Perlik et al. 2001). Consequentially, the human signature on morphology might be less marked (Sofia et al. 2016). At the same time, the anthropogenic signatures on morphology in the Alpine environments reflect the fact that activities are generally shaped through valley bottoms and ridges, and by limits due to the slope and the steepness of the terrain (Forman et al. 2003).

A further interesting result is the striking similarity between the PDFs of vineyards in the plain to hilly (b) and (a)

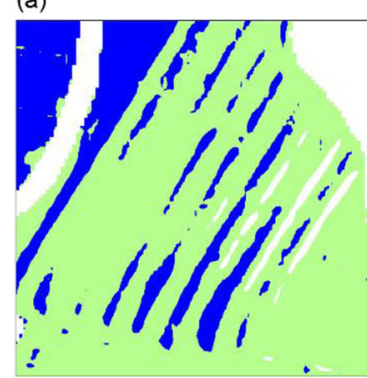

Slope $\left({ }^{\circ}\right)$

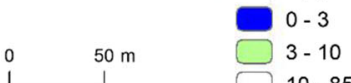

(b)

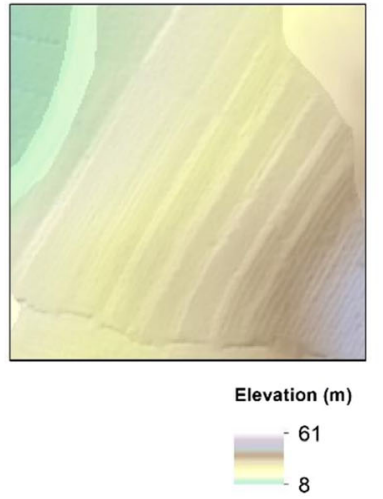

(c)

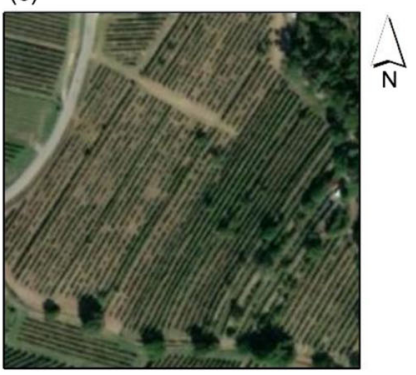

Service Layer Credits: Source: Esri, DigitalGlobe, GeoEye

Fig. 9 Overview of a typical vineyard in the plain to hilly landscape (from (a), the blue color represents the first slope peak value which is the terrace bench, and the green shows the second slope peak value which represents the terrace walls; (b) and (c) presents the corresponding elevation and satellite image) 

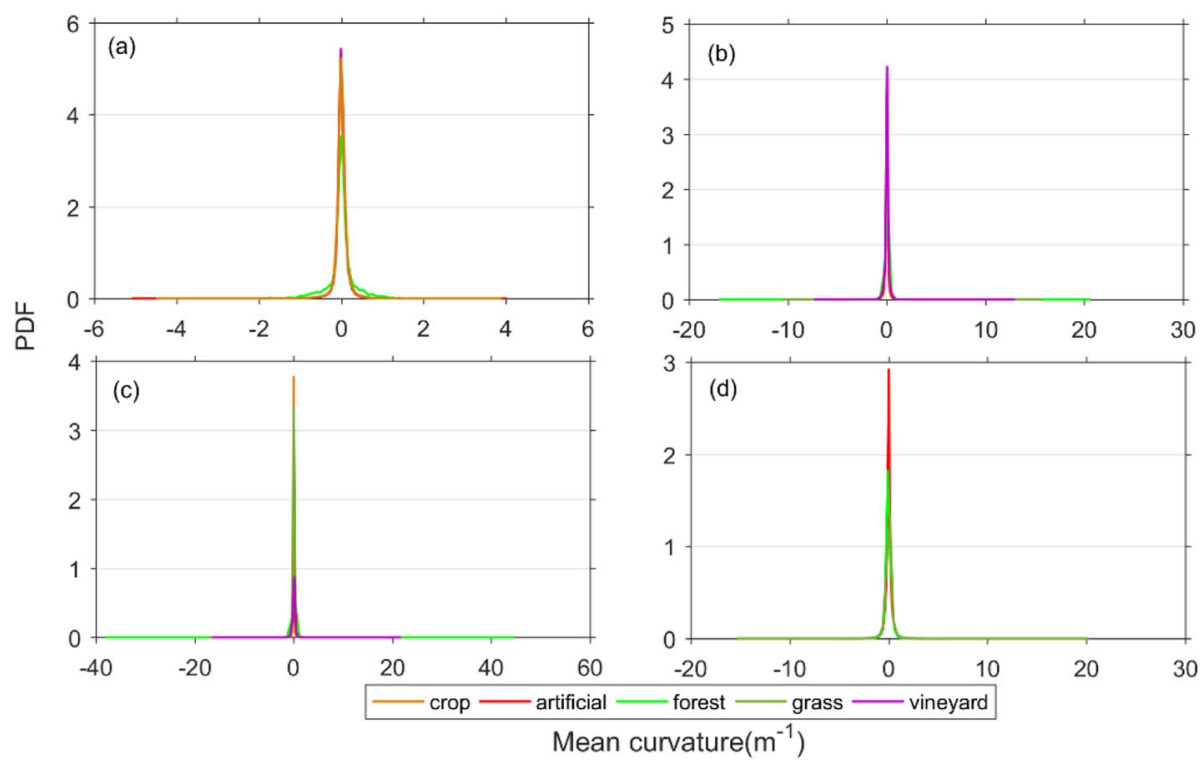

Fig. 10 The PDFs of the mean curvature with different land covers in the four areas: a floodplain, $\mathbf{b}$ plain to hilly, $\mathbf{c}$ hilly, $\mathbf{d}$ mountain

the hilly sites (c): for these landscapes, the PDFs present a double peak.

The first peak falls at a range of $0-3^{\circ}$, while the second peak falls around $3-10^{\circ}$. It is possible to note that in this landscape (Fig. 9), vineyards are constructed over terraces: the terrace walls present slope with the highest values (the second peak); on the other hand, the slope with lower values (the first peak) is related to the terrace benches. This peculiar double peak in terraced landscapes was also showed by (Tarolli and Sofia 2016), for terraces related to urbanisation over hillslopes.

Focusing on mean curvature (Fig. 10), all landforms present a distribution that peaks around 0 . The extreme values on the positive side are related to divergent-

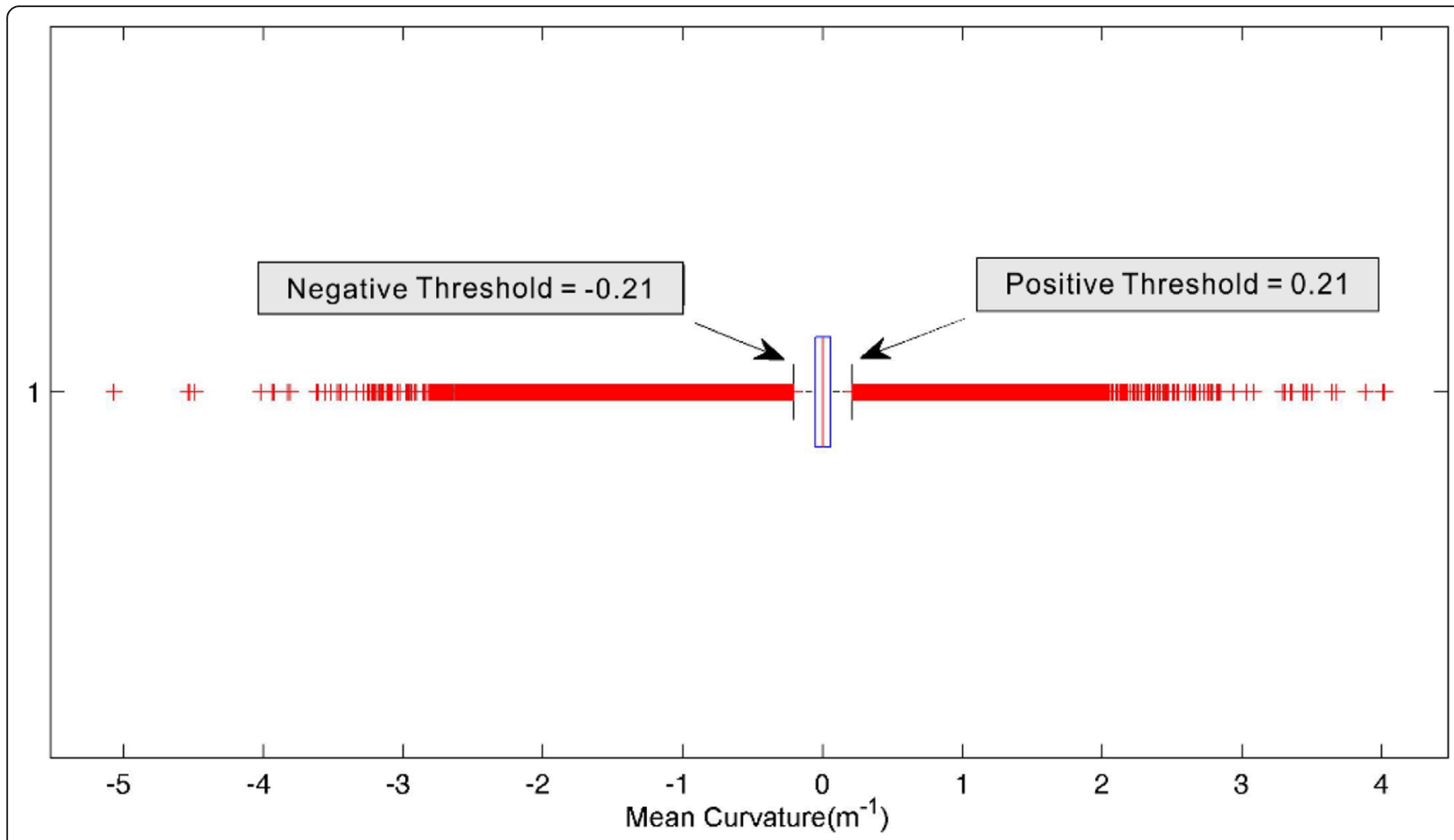

Fig. 11 The boxplot of mean curvature and the negative/positive threshold in the floodplain 
convex landforms, and they are generally associated with the dominance of hillslopes. The presence of extreme values on the negative side is related to convergentconcave landforms associated generally with fluvialdominated erosion (Tarolli et al. 2012; Evans 2013). As shown in Fig. 10, the long tails of extreme value are related to artificial land covers in the floodplain and to forests in the plain to hilly and hilly areas.

To better identify the reason behind these long tails, we used boxplots to detect the positive and negative outliers (Fig. 11) The idea behind this is that convex features can be identified as curvature values above the upper bound, and on the contrary, concave features can be identified as value below the lower bound (Sofia et al. 2014b).

As we can see from the satellite image (Fig. 12), the negative outliers of curvature in the floodplain are mostly related to channel networks, while the positive outliers are related to scarps, levees and small banks around them. Some noise in the curvature map is given by the footprint of the urban area, where negative and positive outliers can be found around buildings. For the hilly area, the outliers on the positive side are related to ridges, while the negative ones are channelized valleys, where forests are mostly present.

\section{Statistic test on the morphology of different land covers under various landforms}

The results of Kruskal-Wallis test (Table 1) show that significant differences $(p<0.05)$ exist among land covers regarding their slope.

Looking at the $p$ values for the Kolmogorov-Smirnov test (Table 2), it is possible to highlight that (1) there are significant differences in slope between any pair of land covers in each case study areas, except for grass and vineyard in hilly sites (marked with asterisk symbol); (2)

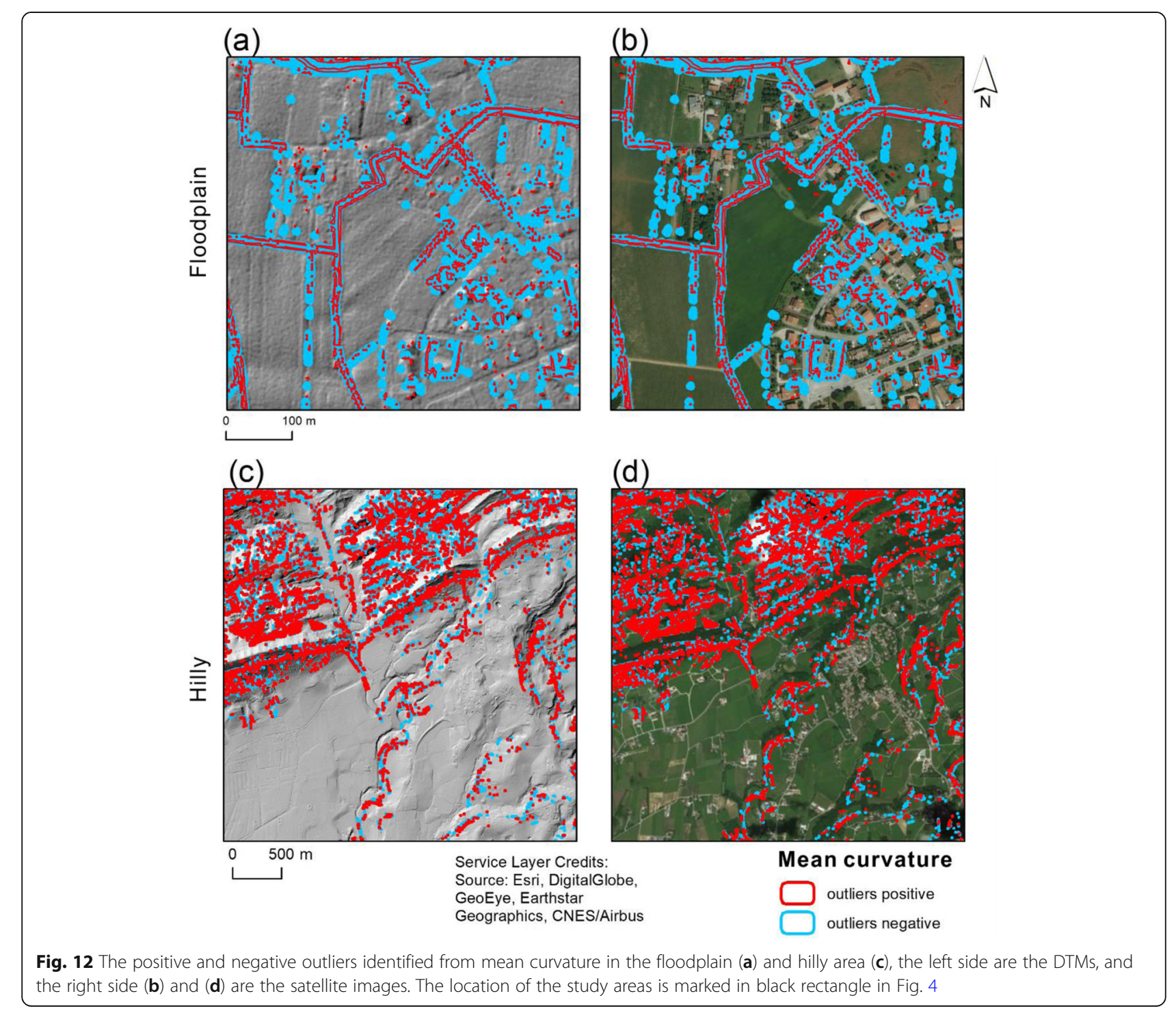


Table 1 Kruskal-Wallis significance tests of difference in slope between different land covers in each study area. Source means the origin of variance, and it includes the variance between groups (different land covers) and error (geomorphometric value in the same land cover); SS means sum of square; MS represent standard deviation, and it could reflect the degree of dispersion of a dataset; chi sq. is the H-statistic of the Kruskal-Wallis test, which is approximately chi-square distributed. The Prob. > chi sq. is the $p$ value

\begin{tabular}{|c|c|c|c|c|c|}
\hline & Source & SS & MS & Chi sq. & Prob. $>$ chi sq. \\
\hline \multirow[t]{3}{*}{ Floodplain } & Groups & $1.22 \mathrm{E}+09$ & $3.04 \mathrm{E}+08$ & 583.76 & $5.06 \mathrm{E}-125$ \\
\hline & Error & $9.20 E+09$ & $1.84 \mathrm{E}+06$ & & \\
\hline & Total & $1.04 E+10$ & & & \\
\hline \multirow[t]{3}{*}{ Plain to hilly } & Groups & $4.23 E+09$ & $1.06 \mathrm{E}+09$ & 2031.16 & 0 \\
\hline & Error & $6.18 \mathrm{E}+09$ & $1.24 \mathrm{E}+06$ & & \\
\hline & Total & $1.04 E+10$ & & & \\
\hline \multirow[t]{3}{*}{ Hilly } & Groups & $5.86 \mathrm{E}+09$ & $1.465 E+09$ & 2813.1 & 0 \\
\hline & Error & $4.55 E+09$ & 911886.3 & & \\
\hline & Total & $1.04 \mathrm{E}+10$ & & & \\
\hline \multirow[t]{3}{*}{ Mountain } & Groups & $5.99 \mathrm{E}+08$ & $2.0 \mathrm{E}+08$ & 449.18 & 4.90E-97 \\
\hline & Error & 4.73E+09 & $1.18 \mathrm{E}+06$ & & \\
\hline & Total & $5.33 E+09$ & & & \\
\hline
\end{tabular}

among all the $p$ value, the most remarkable difference always relates to the forest and any of the other land covers.

We addressed the same analysis on mean curvature. However, the results (Table 3 ) show no significant difference among land covers ( $p$ value $>0.05)$.
As a trial test, we randomly sampled 10,000 points from the maps: with this enlarged dataset, the results show a significant difference among various land covers as a group or pairwise (Tables 4 and 5). Crops and vineyards give exceptions to this in the plain to the hilly area

Table 2 The significance level of two-sample Kolmogorov-Smirnov tests of pairwise differences in slope between land covers within topographic types

\begin{tabular}{|c|c|c|c|c|c|c|}
\hline & Variable & Crop & Forest & Artificial & Grass & Vineyard \\
\hline \multirow[t]{5}{*}{ Floodplain } & Crop & & $1.55 \mathrm{E}-45$ & $3.59 E-27$ & $1.23 \mathrm{E}-44$ & $3.71 E-36$ \\
\hline & Forest & & & $1.55 \mathrm{E}-45$ & $1.23 \mathrm{E}-44$ & $1.55 \mathrm{E}-45$ \\
\hline & Artificial & & & & $5.34 \mathrm{E}-42$ & $1.75 \mathrm{E}-19$ \\
\hline & Grass & & & & & $3.71 E-36$ \\
\hline & Vineyard & & & & & \\
\hline \multirow[t]{5}{*}{ Plain to hilly } & Crop & & $2.21 \mathrm{E}-08$ & 5.96E-06 & $8.24 \mathrm{E}-24$ & $9.25 \mathrm{E}-05$ \\
\hline & Forest & & & $4.26 \mathrm{E}-13$ & 2.69E-29 & $1.27 \mathrm{E}-12$ \\
\hline & Artificial & & & & $1.40 \mathrm{E}-13$ & 5.56E-01 \\
\hline & Grass & & & & & $9.13 \mathrm{E}-18$ \\
\hline & Vineyard & & & & & \\
\hline \multirow[t]{5}{*}{ Hilly } & Crop & & $5.06 \mathrm{E}-30$ & $6.12 \mathrm{E}-07$ & $1.34 \mathrm{E}-15$ & $3.96 \mathrm{E}-16$ \\
\hline & Forest & & & $3.64 \mathrm{E}-23$ & $6.66 \mathrm{E}-19$ & $3.28 \mathrm{E}-17$ \\
\hline & Artificial & & & & $9.25 \mathrm{E}-05$ & $2.45 \mathrm{E}-05$ \\
\hline & Grass & & & & & $0.556^{*}$ \\
\hline & Vineyard & & & & & \\
\hline \multirow[t]{4}{*}{ Mountain } & Crop & & 1.93E-39 & $1.68 \mathrm{E}-31$ & 5.96E-06 & \\
\hline & Forest & & & $9.48 \mathrm{E}-44$ & $2.33 \mathrm{E}-35$ & \\
\hline & Artificial & & & & 1.44E-34 & \\
\hline & Grass & & & & & \\
\hline
\end{tabular}

*(1) there are significant differences in slope between any pair of land covers in each case study areas, except for grass and vineyard in hilly sites; (2) among all the $p$ value, the most remarkable difference always relates to the forest and any of the other land covers. 
Table 3 Kruskal-Wallis significance tests of mean curvature in each study area based on different land covers

\begin{tabular}{|c|c|c|c|c|c|}
\hline & Source & SS & MS & Chi sq. & Prob. $>$ chi sq. \\
\hline \multirow[t]{3}{*}{ Floodplain } & Groups & $1.64 \mathrm{E}+07$ & $4.11 \mathrm{E}+06$ & 7.89 & 0.0958 \\
\hline & Error & $1.04 \mathrm{E}+10$ & $2.08 \mathrm{E}+06$ & & \\
\hline & Total & $1.04 \mathrm{E}+10$ & & & \\
\hline \multirow[t]{3}{*}{ Plain to hilly } & Groups & $9.17 \mathrm{E}+06$ & $2.29 E+06$ & 4.4 & 0.35 \\
\hline & Error & $1.04 \mathrm{E}+10$ & $2.08 \mathrm{E}+06$ & & \\
\hline & Total & $1.04 \mathrm{E}+10$ & & & \\
\hline \multirow[t]{3}{*}{ Hilly } & Groups & $4.58 \mathrm{E}+06$ & $1.15 E+06$ & 2.2 & 0.6991 \\
\hline & Error & $1.04 \mathrm{E}+10$ & $2.08 \mathrm{E}+06$ & & \\
\hline & Total & $1.04 \mathrm{E}+10$ & & & \\
\hline \multirow[t]{3}{*}{ Mountain } & Groups & $3.51 \mathrm{E}+06$ & 1.17E+06 & 2.63 & 0.4516 \\
\hline & Error & $5.33 E+09$ & $1.33 E+06$ & & \\
\hline & Total & $5.33 \mathrm{E}+09$ & & & \\
\hline
\end{tabular}

Table 4 Kruskal-Wallis significance tests of mean curvature in each study area based on different land covers with 10,000 sample

\begin{tabular}{|c|c|c|c|c|c|}
\hline & Source & SS & MS & Chi sq. & Prob. $>$ chi sq \\
\hline \multirow[t]{3}{*}{ Plain to hilly } & Groups & $3.11 \mathrm{E}+09$ & $7.77 \mathrm{E}+08$ & 14.92 & 0.0049 \\
\hline & Error & $1.04 \mathrm{E}+13$ & $2.08 \mathrm{E}+08$ & & \\
\hline & Total & $1.04 \mathrm{E}+13$ & & & \\
\hline \multirow[t]{3}{*}{ Hilly } & Groups & $4.83 E+09$ & $1.21 \mathrm{E}+09$ & 23.21 & 0.0001 \\
\hline & Error & $1.04 \mathrm{E}+13$ & $2.08 \mathrm{E}+08$ & & \\
\hline & Total & $1.04 \mathrm{E}+13$ & & & \\
\hline \multirow[t]{3}{*}{ Mountain } & Groups & $1.12 \mathrm{E}+09$ & $3.73 E+08$ & 8.39 & 0.0386 \\
\hline & Error & $5.33 E+12$ & $1.33 E+08$ & & \\
\hline & Total & $5.33 \mathrm{E}+12$ & & & \\
\hline
\end{tabular}

Table 5 The significant level of two-sample Kolmogorov-Smirnov tests of pairwise differences in mean curvature between land covers within topographic types with 10,000 sample

\begin{tabular}{|c|c|c|c|c|c|c|}
\hline & Variable & Crop & Forest & Artificial & Grass & Vineyard \\
\hline \multirow[t]{5}{*}{ Plain to hilly } & Crop & & 1.19E-129 & 4.60E-03 & $1.66 \mathrm{E}-39$ & $0.4132^{*}$ \\
\hline & Forest & & & $1.03 \mathrm{E}-100$ & $1.59 \mathrm{E}-28$ & 4.62E-132 \\
\hline & Artificial & & & & $1.60 \mathrm{E}-23$ & 0.007 \\
\hline & Grass & & & & & $1.66 \mathrm{E}-39$ \\
\hline & Vineyard & & & & & \\
\hline \multirow[t]{5}{*}{ Hilly } & Crop & & $1.28 \mathrm{E}-270$ & $4.66 \mathrm{E}-58$ & $2.77 \mathrm{E}-63$ & $1.83 \mathrm{E}-26$ \\
\hline & Forest & & & 4.07E-108 & $3.62 \mathrm{E}-91$ & $9.59 \mathrm{E}-140$ \\
\hline & Artificial & & & & $5.95 \mathrm{E}-07$ & $1.42 \mathrm{E}-07$ \\
\hline & Grass & & & & & $3.28 \mathrm{E}-09$ \\
\hline & Vineyard & & & & & \\
\hline \multirow[t]{4}{*}{ Mountain } & Crop & & $0.2791^{*}$ & $6.25 \mathrm{E}-08$ & $1.70 \mathrm{E}-03$ & \\
\hline & Forest & & & $4.64 \mathrm{E}-11$ & $6.11 \mathrm{E}-04$ & \\
\hline & Artificial & & & & $2.37 \mathrm{E}-19$ & \\
\hline & Grass & & & & & \\
\hline
\end{tabular}


and also crop and forest in the mountain area ( $p$ value $>$ 0.05).

When observing the $S p c$ and the result of the KruskalWallis test (Table 6), it is confirmed that the different land covers present different topography signatures ( $p$ value $<0.05)$. The exceptional case which doesn't show the significant difference makred with asterisk symbol.

As it is possible to infer from Table 7: (1) pairwise differences exist in all land covers except for grass and vineyards(marked with asterisk symbol). (2) Forest differentiates from other land covers on the $S p c$, and this is evident for all landforms' context considered.

\section{The distinct anthropogenic impact analysis}

The $S p c$ is mathematically related to the percentage of anthropogenic activity (Chen et al. 2015; Xiang et al. 2018; Xiang et al. 2019). As a consequence, it is a proxy to illustrate the extent of human impact on morphology for each land cover in different landforms (Fig. 13). The most recognisable topographic signature is that given by the forests in the floodplain (Fig. 13a). Besides, the peak of forest distribution (higher due to the small and uniform surface) falls within values of $S p c$ on the range of those obtained in literature for highly anthropogenic surfaces. The forest distribution in both plain to hilly (Fig. 13b) and hilly areas (Fig. 13c) present a similar trend, but the peak in the hilly area tends to be to the right side (where $S p c$ values are referred to be more 'natural' if compared with the mentioned literature). When moving to the mountain (Fig. 13d), the forest shape appears less skewed, which might indicate that lower human interference is present.

In Fig. 14a and b, the map of $S p c$ and forest as seen from the satellite is shown in detail. The forest here is closed to the channel and mostly on the levees. This also gives a reasonable interpretation of the lower value of $S p c$ due to the human alteration on the forest in the floodplain. By contrast, we highlight a small area with different Spc values (Fig. 14c and e, marked with different colours) and the LiDAR-derived shaded relief map (Fig. 14d) in a different area where the transition from plain to hilly is evident. The forests with relatively lower Spc value are located in areas surrounded by agricultural terraces and other anthropogenic surfaces. On the other side, the forests with higher $S p c$ value are distributed on the top of small hills and tend to be more natural. Forest not only presents a remarkable difference with other land covers but also shows a different morphology based on the degree of anthropogenic disturbance.

Xiang et al. (2019) highlighted how morphological differences under forest cover emerged by considering natural forests or artificial plantations, with higher Spc for natural forests. In actuality, the forest (mixed of shrubs and medium trees) in the floodplain area considered in this study have been altered in their structure and distribution, thus appearing as small patches surrounded by agricultural and urban areas, in lands highly disturbed by human activities. Forests in this floodplain are also managed to adopt peculiar forestry technique to preserve and maintain the vegetation, through new plantations near the ancient wood (Bellio and Pividori 2009). Our results confirm that, from a morphological perspective, the described forest for the floodplain is related to a surface affected by anthropogenic pressure, while a lower anthropogenic disturbance might be present on forests on hilly places, with the existence of more natural forests. Some land covers do not exhibit apparent differences in specific landforms. For example, grass and vineyards present some similarities in hilly areas (Table 2). As it is shown on Fig. 15, the floodplain grass (left side) has lower values of $S p c$, which implies that anthropogenic disturbance might be relatively significant in this environment. Taking a closer view (Fig. $15 \mathrm{~d})$, this area is related to a sports field and a park. By

Table 6 Kruskal-Wallis significance tests of Spc in each study area based on different land covers

\begin{tabular}{|c|c|c|c|c|c|}
\hline & & SS & MS & Chi sq. & Prob. > chi sq. \\
\hline \multirow[t]{3}{*}{ Floodplain } & Groups & $8.51 \mathrm{E}+08$ & $2.13 \mathrm{E}+08$ & 408.41 & 4.23E-87 \\
\hline & Error & $9.57 \mathrm{E}+09$ & $1.92 \mathrm{E}+06$ & & \\
\hline & Total & $1.04 \mathrm{E}+10$ & & & \\
\hline \multirow[t]{3}{*}{ Plain to hilly } & Groups & 4.06E+09 & $1.01 \mathrm{E}+09$ & 1948.22 & 0 \\
\hline & Error & $6.36 \mathrm{E}+09$ & $1.27 \mathrm{E}+06$ & & \\
\hline & Total & $1.04 \mathrm{E}+10$ & & & \\
\hline \multirow[t]{3}{*}{ Hilly } & Groups & $2.12 \mathrm{E}+09$ & $5.30 \mathrm{E}+08$ & 1017.81 & $4.92 \mathrm{E}-219$ \\
\hline & Error & $8.30 E+09$ & $1.66 \mathrm{E}+06$ & & \\
\hline & Total & $1.04 \mathrm{E}+10$ & & & \\
\hline \multirow[t]{3}{*}{ Mountain } & Groups & $2.63 E+09$ & $8.76 \mathrm{E}+08$ & 1969.43 & 0 \\
\hline & Error & 2.71E+09 & 677369.2 & & \\
\hline & Total & $5.33 E+09$ & & & \\
\hline
\end{tabular}

"it is confirmed that the different land covers present different topography signatures ( $p$ value $<0.05$ ). 
Table 7 The significant level of two-sample Kolmogorov-Smirnov test of pairwise differences in Spc between land covers within topographic types

\begin{tabular}{|c|c|c|c|c|c|c|}
\hline & Variable & Crop & Forest & Artificial & Grass & Vineyard \\
\hline \multirow[t]{5}{*}{ Floodplain } & Crop & & $1.55 \mathrm{E}-45$ & 3.97E-25 & $1.23 \mathrm{E}-44$ & $3.88 \mathrm{E}-41$ \\
\hline & Forest & & & 1.55E-45 & $1.55 E-45$ & $1.55 E-45$ \\
\hline & Artificial & & & & 7.19E-43 & $1.43 \mathrm{E}-14$ \\
\hline & Grass & & & & & $5.11 \mathrm{E}-33$ \\
\hline & Vineyard & & & & & \\
\hline \multirow[t]{5}{*}{ Plain to hilly } & Crop & & $4.26 \mathrm{E}-13$ & 2.45E-05 & 7.17E-28 & 1.80E-03 \\
\hline & Forest & & & 1.12E-20 & $8.66 \mathrm{E}-34$ & $4.48 \mathrm{E}-20$ \\
\hline & Artificial & & & & $9.13 \mathrm{E}-18$ & 0.677 \\
\hline & Grass & & & & & $6.67 \mathrm{E}-22$ \\
\hline & Vineyard & & & & & \\
\hline \multirow[t]{5}{*}{ Hilly } & Crop & & $5.06 \mathrm{E}-30$ & 4.81E-05 & 4.41E-15 & $1.27 \mathrm{E}-12$ \\
\hline & Forest & & & 8.44E-26 & $4.48 \mathrm{E}-20$ & $1.15 \mathrm{E}-16$ \\
\hline & Artificial & & & & 2.21E-08 & $2.85 \mathrm{E}-06$ \\
\hline & Grass & & & & & $0.26^{*}$ \\
\hline & Vineyard & & & & & \\
\hline \multirow[t]{4}{*}{ Mountain } & Crop & & $5.77 \mathrm{E}-37$ & $1.40 \mathrm{E}-28$ & $1.21 \mathrm{E}-07$ & \\
\hline & Forest & & & 1.23E-44 & 2.33E-35 & \\
\hline & Artificial & & & & 5.77E-37 & \\
\hline & Grass & & & & & \\
\hline
\end{tabular}

"(1) pairwise differences exist in all land covers except for grass and vineyards. (2) Forest differentiates from other land covers on the Spc, and this is evident for all landforms' context considered.
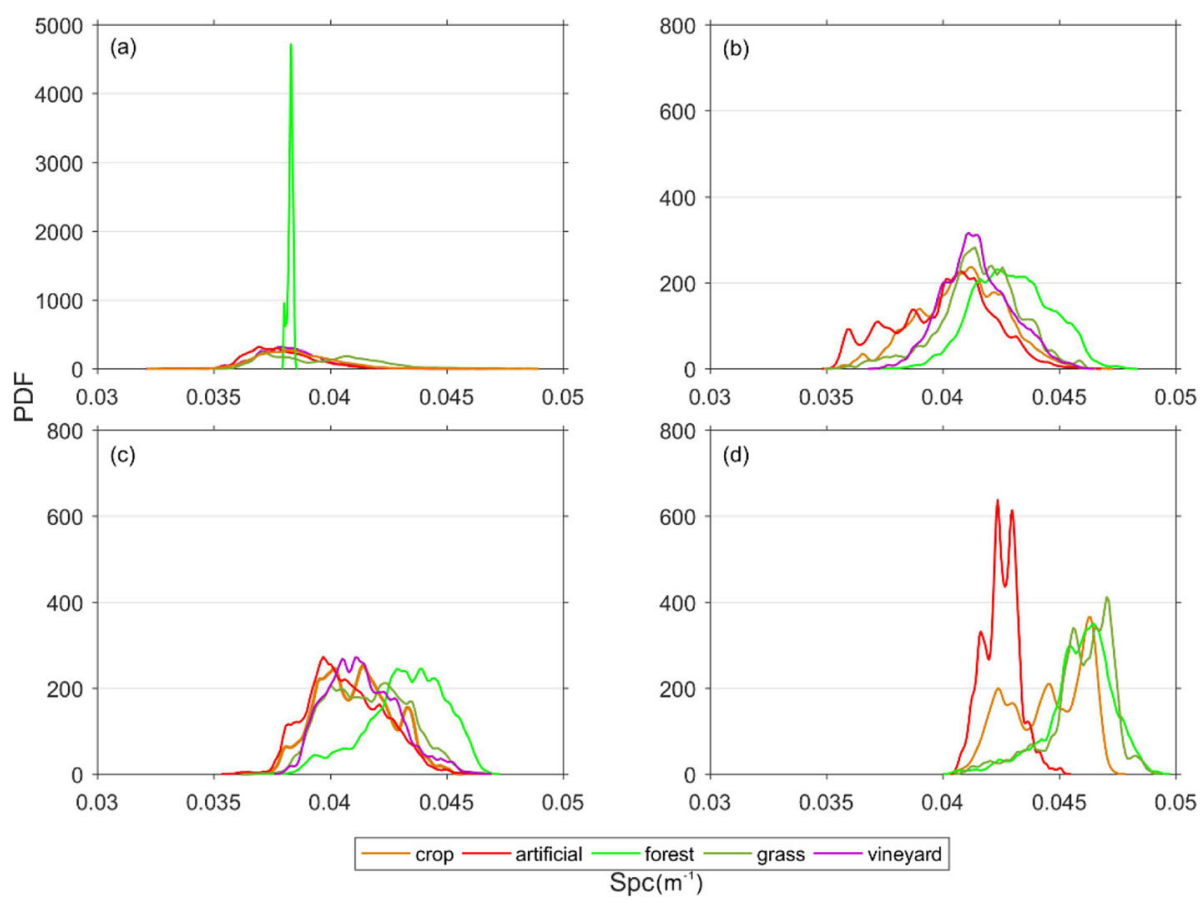

Fig. 13 The PDFs of the Spc. with different land covers in the four areas. a floodplain, b plain to hilly, c hilly, d mountain 

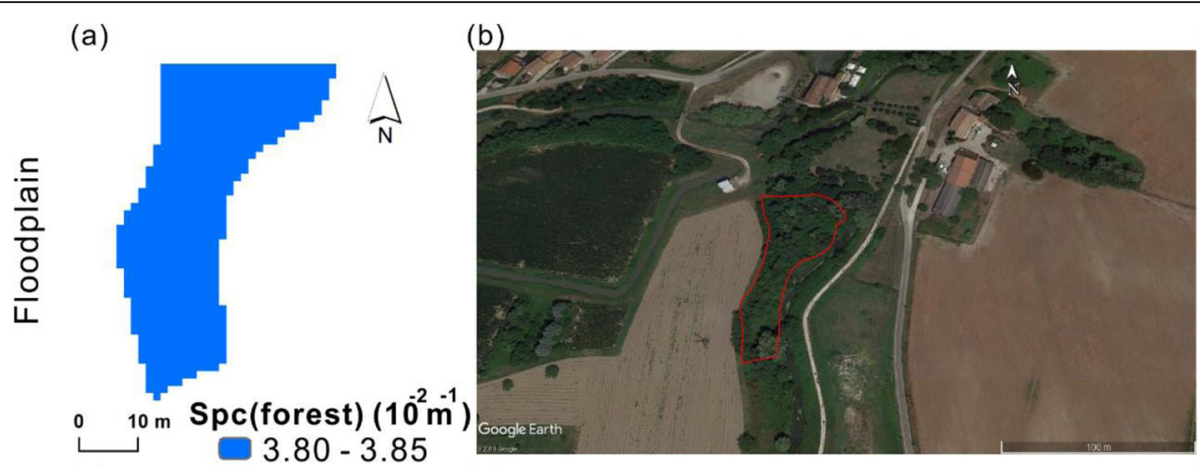

(c)

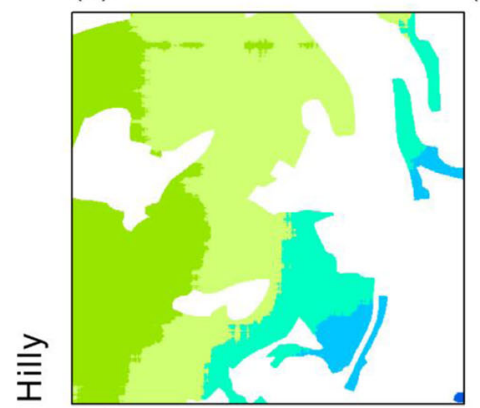

(e) (d)
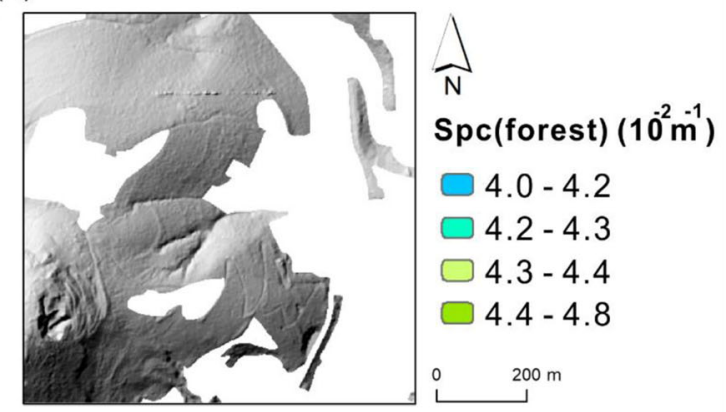

$4.0-4.2$

$4.2-4.3$

$4.3-4.4$

$4.4-4.8$

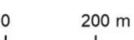

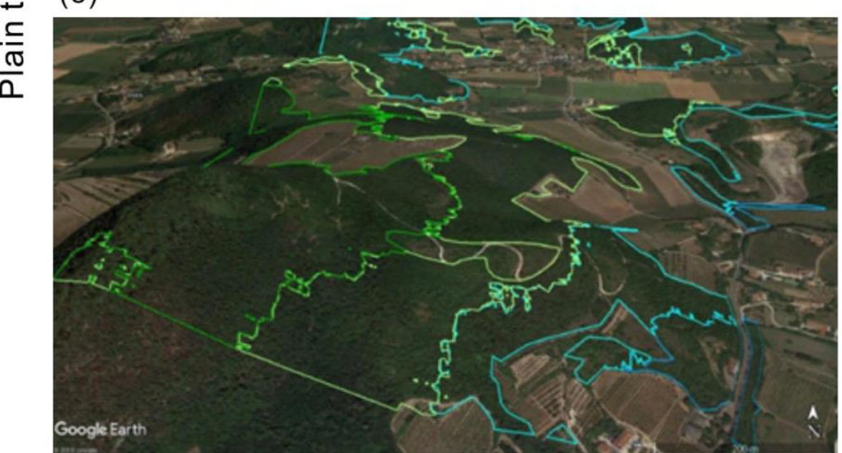

Fig. 14 Forest with Spc value in floodplain (a) and 3D overview (b) of the surrounding from Google Earth (the red outline extracted from forest); forest with $S p c$ value in plain to hilly (c), LiDAR (d) and 3D overview (e); the outline with different colour denote the different Spc values

contrast, the grass in the hilly area (right side) shows a relatively higher $S p c$ value than that of the floodplain. This could imply that anthropogenic modifications in this grassland still exist, even though there are less marked than in floodplain, and from the satellite image (Fig. 15h), the grass in hilly can be identified as pastures.

The similarities in morphology $(S p c)$ between grass and vineyard in hilly areas can be explained by the fact these pastures are intensively farmed to maximise forage production. Some of them have been abandoned ('prati vegri') or converted to vineyards. Therefore, the humanmorphological signature is still evident and appears in the $S p c$.

\section{Conclusions}

The primary goal of this work was to investigate the statistical differences of surface morphologies of anthropogenic and natural land covers, testifying that human activities alter the landforms from a statistical point of view. The work highlights how, if we were to make quantitative measurements of landscape properties on a landscape without human interference, and compare them to measurements of a landscape where humans activities are preponderant; the frequency distributions of these measurements would be very different, even though all observed landform types would be found in both realities. Possibly, if we had to model and describe a landscape without humans, it would look much different from the one we are used to, but it would not exhibit much different landforms. Rather, the subtle differences would lie in the frequency distributions of specific landform properties. This work also confirms the possibility to recognise with a pure geomorphometric analysis the signatures of anthropogenic activities within a specific landscape context and further demonstrate how 

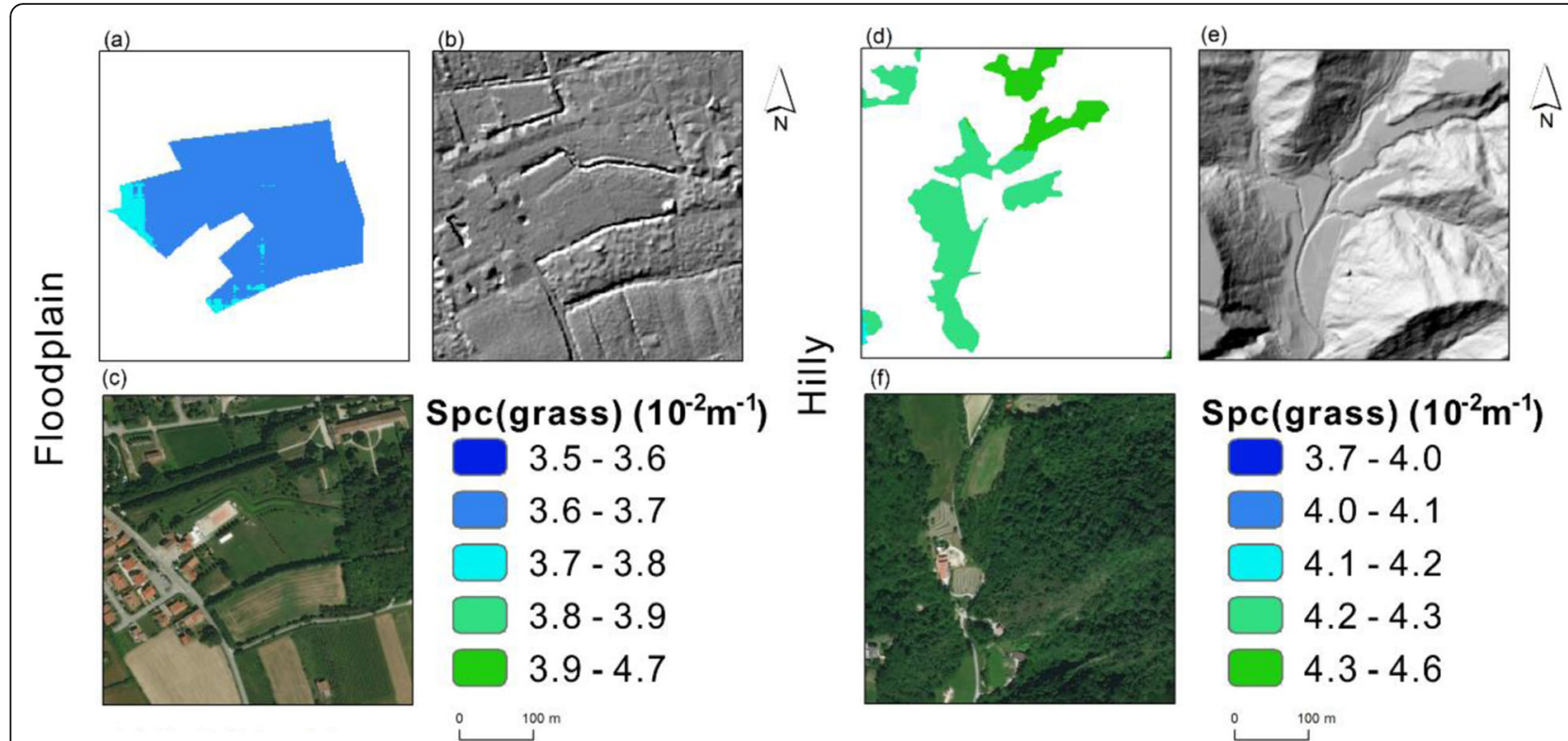

Fig. 15 Grass with Spc value in floodplain (a) and hilly (d), LiDAR-derived shaded relief map in floodplain (b) and hilly (e), and satellite image in floodplain (c) and hilly (f); panels $\mathbf{d}$ and $\mathbf{f}$ are the 3D view from Google map in these two study areas

people use of the land changes the Earth surface in three dimensions. Different utilisations of the same land cover show a different extent of anthropogenic impacts, underlining the opportunity for future analyses of the 'magnitude' and 'type' of human forcing on Earth. The results provide robust evidence of the human activity's impact on some terrestrial surfaces, fostering therefore future studies linking the relationship between humans, land use, and geomorphological alterations. Our study offers a new insight to understand the present geomorphology coupling the function of human activities and poses a challenge for future research of the geomorphic and human systems in a world increasingly affected by anthropogenic activities.

\section{Supplementary information}

Supplementary information accompanies this paper at https://doi.org/10. 1186/s40645-019-0314-x.

Additional file 1. Supplement 1: Statistic values (mean, median, STD MAD, skewness...) of each geomorphometric parameter within each land cover Supplement 2: SLLAC maps for the four study areas (a) floodplain (b) plain to hilly (c) hilly (d) mountain.

\section{Abbreviations}

CLC: Corine-Land-Cover; DTMs: Digital Terrain Models; LiDAR: Light Detection And Ranging; PDF: Probability Density Function; SLLAC: Slope Local Length of Auto-Correlation; Spc: Surface peak curvature

\section{Acknowledgements}

The authors thank Dr. Martino Bernard for the help with MATLAB coding and Dr. Zihua Cheng for the fruitful discussion on the statistical analysis. The authors are also grateful to the editor, Prof. Yuichi S. Hayakawa (The University of Tokyo, Center for Spatial Information Science Japan) and anonymous reviewers for constructive review comments, which led to significant improvements in the manuscript.

\section{Authors' contributions}

PT proposed the topic; PT and CWF designed the study; CWF performed research and analysed data; CWF collaborated with GS in the construction and writing the manuscript; PT supervised the entire work. All authors read and approve the final manuscript.

\section{Funding}

This work was supported by Chinese Scholarship Council (201606670005).

\section{Availability of data and materials}

The datasets supporting the results of this article are included within the article and its supplements.

\section{Competing interests}

The authors declare that they have no competing interest.

\section{Author details}

'Department of Land, Environment, Agriculture and Forestry, University of Padova, Agripolis, viale dell'Università 16, Legnaro (PD) 35020, Italy.

${ }^{2}$ Department of Civil \& Environmental Engineering, University of Connecticut, 261 Glenbrook Rd, Storrs, USA.

Received: 10 June 2019 Accepted: 22 November 2019

Published online: 08 January 2020

\section{References}

Bellio B, Pividori P (2009) Caratteri strutturali in giovani impianti planiziali a prevalenza di farnia e carpino bianco nel Veneto. SISEF - Italian Society of Silviculture and Forest Ecology. https://doi.org/10.3832/efor0554-006 Bolongaro-Crevenna A, Torres-Rodríguez V , Sorani V, Frame D, Arturo M (2005) Geomorphometric analysis for characterizing landforms in Morelos State, Mexico. Geomorphology 67:407-422

Borrelli P, Robinson DA, Fleischer LR, Lugato E, Ballabio C, Alewell C, Meusburger K, Modugno S, Schütt B, Ferro V, Bagarello V, Oost KV, Montanarella L,Panagos P (2017) An assessment of the global impact of 21st century land use change on soil erosion. Nature Communications 8 (1): 2013

Brown AG, Tooth S, Bullard JE, Thomas D, Chiverrell RC, Plater AJ, Murton J, Thorndycraft VR, Tarolli P, Rose J, Wainwright J, Downs P, Aalto R (2017) The geomorphology of the Anthropocene: emergence, status and implications. Earth Surface Processes and Landforms 42:71-90

Byun J, Seong YB (2015) An algorithm to extract more accurate stream longitudinal profiles from unfilled DEMs. Geomorphology 242:38-48 
Castelltort S, Whittaker A, Vergés J (2015) Tectonics, sedimentation and surface processes: from the erosional engine to basin deposition. Earth Surface Processes and Landforms 40:1839-1846

Chen J, Li K, Chang KJ, Sofia G, Tarolli P (2015) Open-pit mining geomorphic feature characterisation. International Journal of Applied Earth Observation and Geoinformation 42:76-86

Csima P (2010) Urban development and anthropogenic geomorphology. In: Szabó J, Dávid L, Lóczy D (eds) Anthropogenic geomorphology. Springer, Dordrecht

Curebal I, Efe R, Soykan A, Sonmez S (2015) Impacts of anthropogenic factors on land degradation during the anthropocene in Turkey. J Environ Biol 36:51

Dietrich WE, Perron JT (2006) The search for a topographic signature of life. Nature 439:411

Ellis EC (2004) Long-term ecological changes in the densely populated rural landscapes of China. American Geophysical Union. https:/doi.org/10.1029/153GM23

Ellis EC, Fuller DQ, Kaplan JO, Lutters WG (2013) Dating the Anthropocene: towards an empirical global history of human transformation of the terrestrial biosphere. Elementa: Science of the Anthropocene 1, p.000018, doi: 10.12952/journal.elementa.000018

European Environment Agency (2012) Under the framework of the Copernicus Programme. https://land.copernicus.eu/local/urban-atlas/urban-atlas-2012 ?tab=metadata. Accessed 04 Aug 2018

Evans IS (2013) Land surface derivatives: history, calculation and further development. Geomoprhometry Org:1-4

Evans S (1980) An integrated system of terrain analysis and slope mapping. Geomorphologie, Suppl. - Bd 36: 274-295

Forman RTT, Sperling D, Bissonette JA, Clevenger AP, Cutshall CD, Dale VH (2003) Road ecology: science and solutions. Isl. Press. Washington, D.C.,USA

Goudie A (2018) The human impact in geomorphology - 50 years of change. Geomorphology. https://doi.org/10.1016/j.geomorph.2018.12.002

Goudie AS, Viles HA (2016) Geomorphology in the Anthropocene. Cambridge, UK

Hooke R (2012) Land transfomation by humans: a review. GSA Today 22:4-10

ISO (2013) ISO 25178-2:2013: Geometrical product specifications (GPS) - surface texture: areal -- Part 2: terms, definitions and surface texture parameters. ISO, London

Jordan H, Hamilton K, Lawley R, Price SJ (2016) Anthropogenic contribution to the geological and geomorphological record: A case study from Great Yarmouth, Norfolk, UK. Geomorphology 253:534-546

Kleman J, Borgström I, Skelton A, Hall A (2016) Landscape evolution and landform inheritance in tectonically active regions: the case of the Southwestern Peloponnese, Greece. Zeitschrift Für Geomorphologie 60:171-193

Marshall JA, Roering JJ, Gavin DG, Granger DE (2017) Late Quaternary climatic controls on erosion rates and geomorphic processes in western Oregon, USA. GSA Bulletin 129:715-731

McKight PE, Najab J (2010) Kruskal-Wallis Test. Corsini Encyclopedia of Psychology. https://doi.org/10.1002/9780470479216.corpsy0491

Migoń P, Latocha A (2018) Human impact and geomorphic change through time in the Sudetes, Central Europe. Quaternary International 470:194-206

Nagel DE, Buffington, J M, Parkes SL, Wenger S, Goode JR (2014) A landscape scale valley confinement algorithm: delineating unconfined valley bottoms for geomorphic, aquatic, and riparian applications. Gen. Tech. Rep. RMRS-GTR-321 321:42

Oldroyd DR, Grapes, RH (2008) Contributions to the history of geomorphology and Quaternary geology: an introduction:1-17

Penna D, Borga M, Aronica GT, Brigandi G, Tarolli P (2014) The influence of grid resolution on the prediction of natural and road-related shallow landslides. Hydrology and Earth System Sciences 18 (6):2127-2139

Perlik M, Messerli P, Batzing W (2001) Towns in the Alps: urbanization processes, economic structure, and demarcation of European functional urban areas (EFUAs) in the Alps. Mt. Res. Dev. UNIV CALIF PRESS 21:243-252

Pietrasiak N, Drenovsky RE, Santiago LS, Graham RC (2014) Geomorphology biogeomorphology of a Mojave Desert landscape - configurations and feedbacks of abiotic and biotic land surfaces during landform evolution. Geomorphology 206:23-36

Poeppl RE, Keesstra SD, Maroulis J (2017) A conceptual connectivity framework for understanding geomorphic change in human-impacted fluvial systems. Geomorphology 277:237-250

Ramos-Scharrón CE (2018) Land disturbance effects of roads in runoff and sediment production on dry-tropical settings. Geoderma 310:107-119

Razali NM, Wah YB (2011) Power comparisons of Shapiro-Wilk, KolmogorovSmirnov, Lilliefors and Anderson-Darling tests. Journal of Statistical Modeling and Analytics 2:21-33

Regione del Veneto (2012) Prezzario regionale on-line 2012. https://www.regione. veneto.it. Accessed 20 May 2018
Sidle RC, Ziegler AD (2012) The dilemma of mountain roads. Nature Geoscience 5 (7):437-438

Sofia G, Dalla Fontana G, Tarolli P (2014b) High-resolution topography and anthropogenic feature extraction: testing geomorphometric parameters in floodplains. Hydrological Processes 28:2046-2061

Sofia G, Marinello F, Tarolli P (2014a) A new landscape metric for the identification of terraced sites: the slope local length of auto-correlation (SLLAC). ISPRS Journal of Photogrammetry and Remote Sensing 96:123-133

Sofia G, Marinello F, Tarolli P (2016) Metrics for quantifying anthropogenic impacts on geomorphology: road networks. Earth Surface Processes and Landforms 41:240-255

Sofia G, Roder G, Dalla Fontana G, Tarolli P (2017) Flood dynamics in urbanised landscapes: 100 years of climate and humans' interaction. Scientific Reports 7:40527

Steiger J, Corenblit D (2012) The emergence of an "evolutionary geomorphology"? Central European Journal of Geosciences 4:376-382

Szabó J, Dávid L, Lóczy D (2010) Anthropogenic geomorphology:a guide to manmade landforms. Springer Science \& Business Media, Netherland

Tarolli P (2014) High-resolution topography for understanding Earth surface processes: opportunities and challenges. Geomorphology 216:295-312

Tarolli P, Cao W, Sofia G, Evans D, Ellis EC (2019) From features to fingerprints: a general diagnostic framework for anthropogenic geomorphology. Progress in Physical Geography: Earth and Environment 43:95-128

Tarolli P (2016) Humans and the Earth's surface. Earth Surface Processes and Landforms 41 (15):2301-2304

Tarolli P, Sofia G (2016) Human topographic signatures and derived geomorphic processes across landscapes. Geomorphology 255:140-161

Tarolli P, Sofia G, Dalla Fontana G (2012) Geomorphic features extraction from high-resolution topography: landslide crowns and bank erosion. Natural Hazards 61:65-83

Tessler ZD, Vörösmarty CJ, Grossberg M, Gladkova I, Aizenman H (2016) A global empirical typology of anthropogenic drivers of environmental change in deltas. Sustainability Science 11:525-537

Tóth C (2010) Agriculture: grazing lands and other grasslands. In Anthropogenic Geomorphology (69-82). Springer

Wang S, Fu BJ, Piao S, Lü Y, Ciais P, Feng X, Wang Y (2016) Reduced sediment transport in the Yellow River due to anthropogenic changes. Nat Geosci 9:38

Whitehouse DJ. (2011) Characterization. In Handbook of surface and nanometrology, nanometrology, 2nd edn. CRC Press: Boca Raton, FL 5-170

Wilcox R (2005) Kolmogorov-smirnov test. Encyclopedia of Biostatistics. https:// doi.org/10.1002/0470011815.b2a15064

Wilson JP, Gallant JC (2000) Digital terrain analysis. Terrain analysis: principles and applications 1988:1-21

Wood J (1996) The geomorhological characterisation of digital elevation models. Ph.D. Thesis, University of Leicester

Xiang J, Chen J, Sofia G, Tian Y, Tarolli P (2018) Open-pit mine geomorphic changes analysis using multi-temporal UAV survey. Environmental Earth Science 77:220

Xiang J, Li S, Xiao K, Chen J, Sofia G, Tarolli P (2019) Quantitative analysis of anthropogenic morphologies based on multi-temporal high-resolution topography. Remote Sensing 11:1493

Zhang JY, Yin A, Liu WC, Ding L, Xu XM (2016) First geomorphological and sedimentological evidence for the combined tectonic and climate control on Quaternary Yarlung river diversion in the eastern Himalaya. Lithosphere 8: 293-316

\section{Publisher's Note}

Springer Nature remains neutral with regard to jurisdictional claims in published maps and institutional affiliations. 